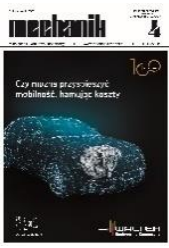

How to cite this article:

Authors: Agnieszka Nowacka, Tomasz Klepka

Title of article: „The application of polymers as abrasive media in abrasive flow machining”

Mechanik, No. 4 (2019)

DOI: https://doi.org/10.17814/mechanik.2019.4.32

\title{
The application of polymers as abrasive media in abrasive flow machining
}

\author{
AGNIESZKA NOWACKA \\ TOMASZ KLEPKA *
}

Mgr inż. Agnieszka Nowacka (a.nowacka@pollub.pl), https://orcid.org/0000-0002-2796-9626 - Politechnika Lubelska, Wydział Mechaniczny, Katedra Technologii i Przetwórstwa Tworzyw Polimerowych, Lublin, Polska

Dr hab. inż. Tomasz Klepka (t.kleppka@pollub.pl) https://orcid.org/0000-0001-9182-0845 - Politechnika Lubelska, Wydział Mechaniczny, Katedra Technologii i Przetwórstwa Tworzyw Polimerowych, Lublin, Polska

The characteristics of the products' treatment by the abrasive flow machining (AFM) makes it an appropriate method of finishing the surface with complex geometry, e.g. holes or channels. Traditional methods of machining cause difficulties in obtaining a homogeneous roughness during finishing complicated shapes due to uneven distribution of abrasive forces. Due to the high price of abrasive media, not every user can afford for using it for processing. In the frame of the research, the novelty abrasive media has been developed to improve the surface roughness of the elements of polymer products. The use of viscoelastic polymers as a media of flow abrasive machining was discussed. Moreover, it is suggested to modify the quantity and size of abrasive grains filling the abrasive media in order to increase the value of the grain pressure force on the machined surface and to obtain an even surface of complex holes in AFM process.

KEYWORDS: abrasive flow machining, viscoelastic polymers, tribology

\section{Characteristics of abrasive flow machining}

Currently, polymeric materials are widely used in many different fields of technology. Polymer materials are increasingly replacing traditional construction materials; they can be used to make machine and mechanism elements or to use them as functional materials. The growing interest in modern polymeric materials means that scientific information related to specialist literature - regarding the complex chemical structure of plastics and the possibility of modifying their properties and properties during processing - can be useful for specialists in various fields of science and technology [1].

Abrasive flow machining uses a deformable abrasive tool - the so-called flexible media pressed under pressure to finish the inside surface of the machined holes [2]. An alternative to the standard medium, which has a high market price, are polymeric materials that can provide viscoelastic properties of abrasive pastes. Machining model and distribution of component forces during the AFM process are shown in fig. 1.

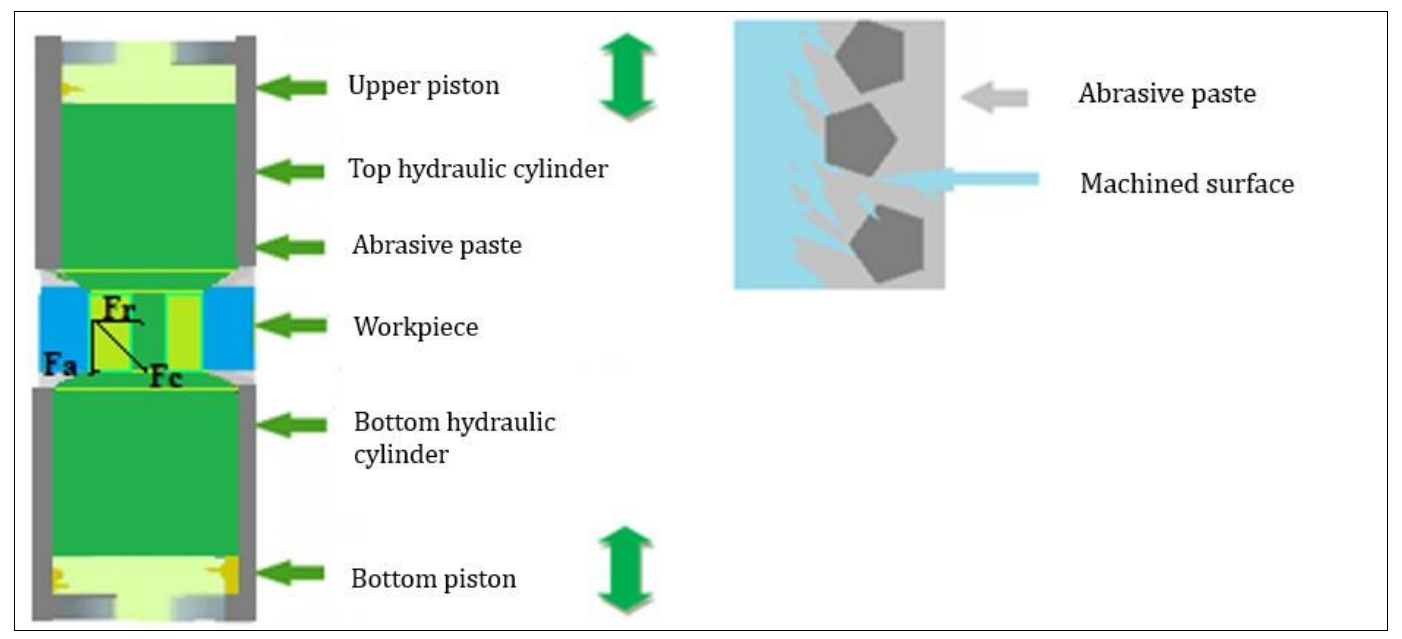

Fig. 1. The essence of abrasive flow machining: a) forcing the medium through the workpiece (Fa force from the paste moving through the piston, $F r$ - force from the viscoelastic paste, $F C$ - the total force of the abrasive grain, affecting the surface being machined), b) micro-cutting process of the workpiece 


\section{Materials and characteristics of the research}

Cross-linked polyvinyl alcohols can be successfully used as viscoelastic polymeric materials. In this case, the polymer medium is a non-Newtonian liquid and its viscosity changes during the process depending on the applied pressure [3]. The abrasive paste used in the machining process consists of a flexible medium (fig. 2) and abrasive grains (fig. 3).<smiles>C=C[Si](C)(I)O[Al]O[Si](C)(C)[IH][Si](C)(C)C</smiles>

Fig. 2. Composition of the silicone polymer medium
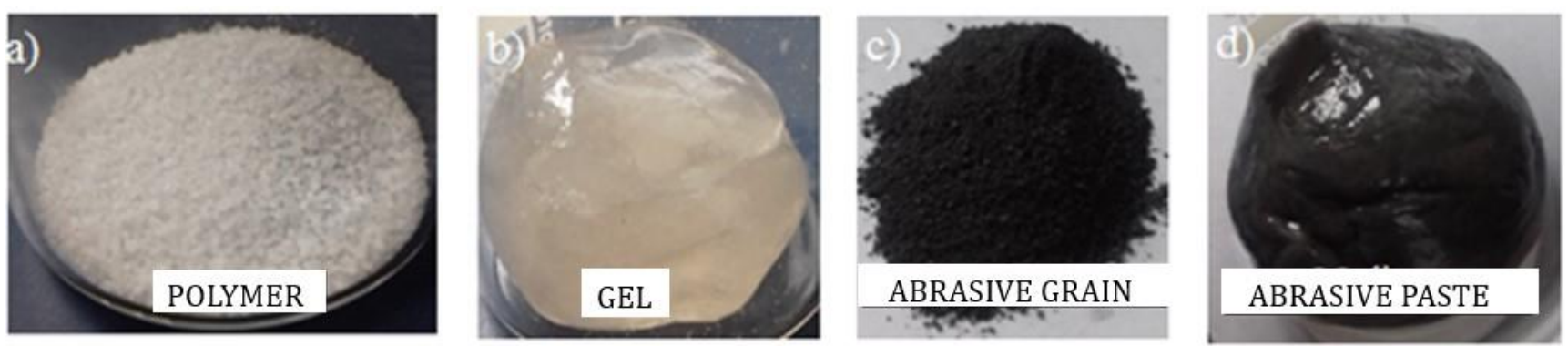

Fig. 3. Components (a-c) and ready abrasive paste (d)

To obtain the desired quality of the machined surface, the type and size of abrasive grains made of polymer materials should be appropriately selected [4]. In publication [5], it was found that, when choosing grains for processing, one should take into account the amount of allowance to be removed and the contact surface of the grain and machined surface. If the grain size and concentration are too large in relation to the volume of the medium, then it is not possible to obtain a high-quality surface without damage $[6,7]$. The principle of using larger grains in abrasive paste applies when removing a considerable amount of allowance from the workpiece and in the case of a large contact surface of the abrasive grain with the surface to be treated. However, the use of larger grains in abrasive paste creates problems with obtaining an adequate flow speed and grain wear due to friction inside the plastic mass volume [8]. Compressed stresses arise in the pressed plastic mass, which causes an increase in the concentration of active grains (in contact with the surface being machined). These grains are pressed against the surface to be machined and, as a result, micro-cutting process takes place [9]. Based on the work [9-11], it can be concluded that the problem of choosing the size and concentration of abrasive paste grains in relation to the desired finish quality of polymeric plastic products has not been described in sufficient detail. Also, due to the high price of the abrasive medium used in abrasive flow machining, there is a need to undertake research into the development of effective abrasive media for machining of the polymer materials.

\section{Preparation of the abrasive medium and machining process parameters}

Products made of polycarbonate (PC) and acrylonitrile-butadiene-styrene (ABS) were selected as finishing objects. These are examples of machine holders.

Fig. 4 shows the procedure for producing the medium and for conducting the abrasive flow machining process. Viscosity of the obtained medium depends on the increase in shear stress (fig. 5).

Machining was carried out at a stand designed to perform tests, presented schematically in fig. 6.

To determine the effect of the grain size used on the quality of the finishing of polymer products, their internal surfaces were machined using 12 polymer abrasive pastes with different grain sizes. The grain size of abrasives is given in tab. I. Contents $Z 1=5 \%, Z 2=15 \%$ and $Z 3=30 \%$ express the percentage of abrasive grains in the polymer medium. Granularity and content of abrasive material in the tested polymer pastes are presented in tab. II. The abrasive grain size was determined according to PN-76/M-59107. 


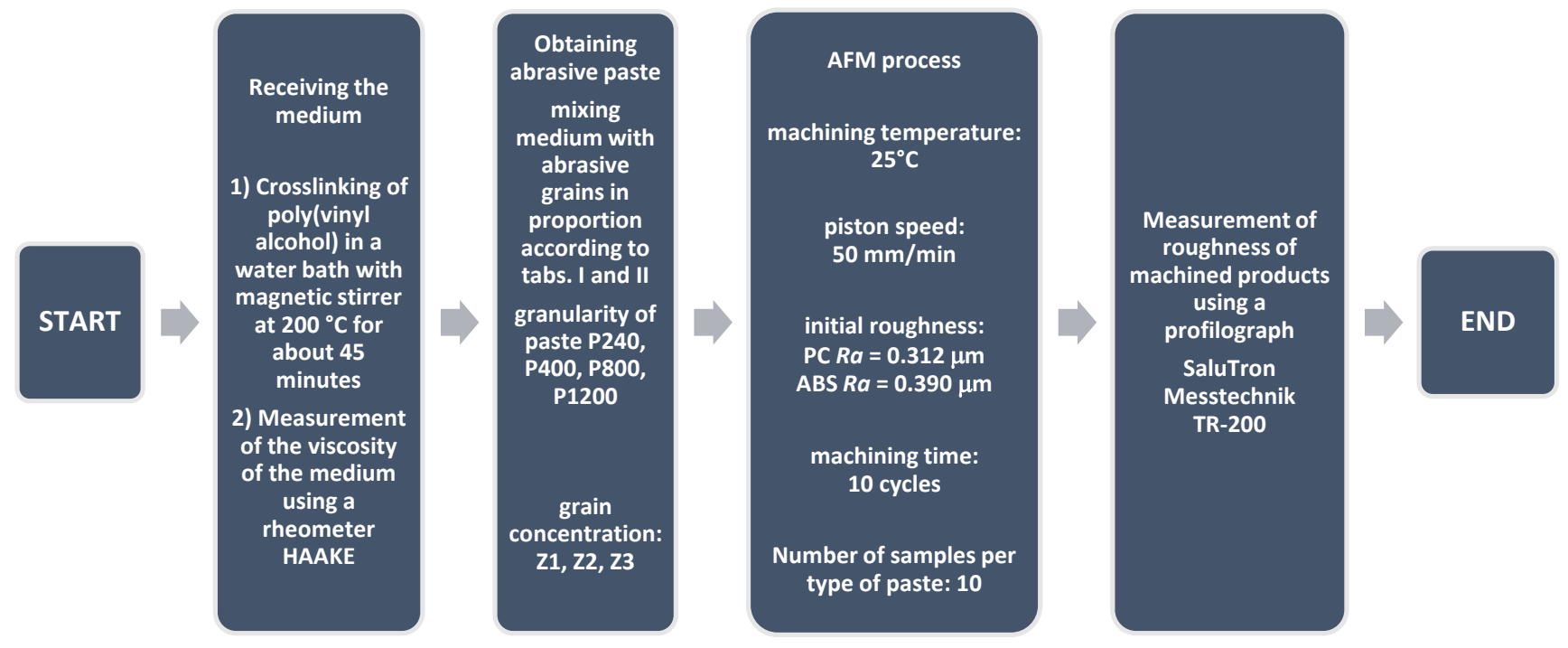

Fig. 4. Procedure for preparing abrasive paste and for carrying out the abrasive flow machining of polymer products

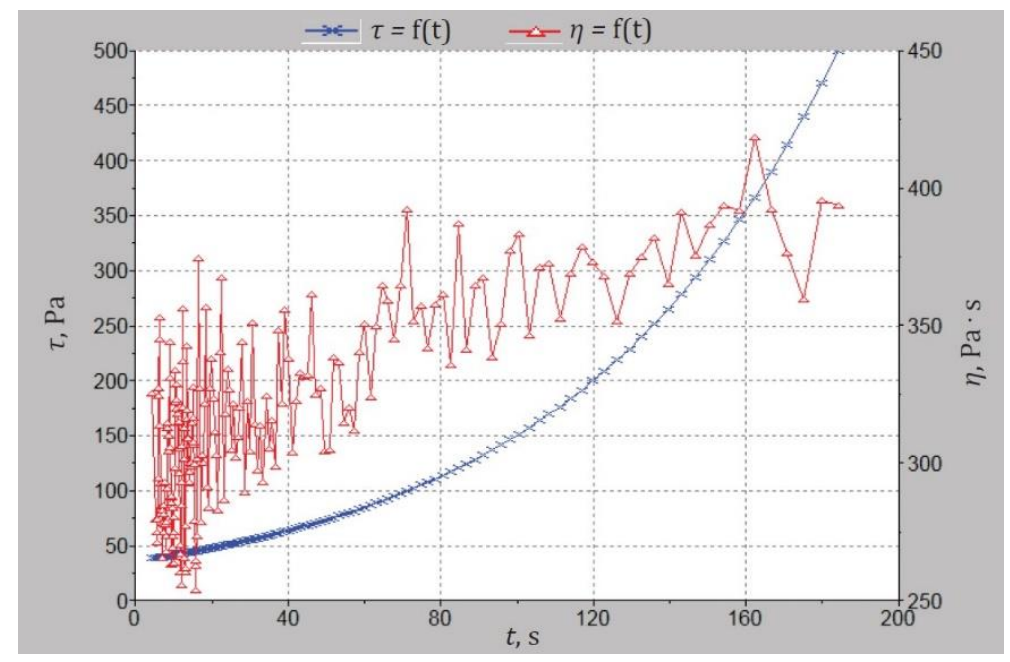

Fig. 5. Diagram of the viscosity of the medium depending on the increase in shear stress during the measurement

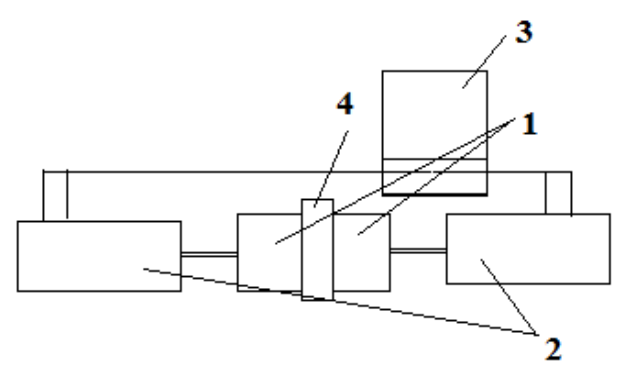

Fig. 6. Diagram of the test stand for abrasive flow machining: 1 - working cylinder, 2 - piston arrangement, 3 - control system, 4 - workpiece

TABLE I. Granularity of abrasive in polymer abrasive paste

\begin{tabular}{|c|c|c|}
\hline \multirow{2}{*}{ Granularity of abrasive } & \multicolumn{2}{|c|}{ Characteristic dimension, $\mu \mathrm{m}$} \\
\cline { 2 - 3 } & from & up to (inclusive) \\
\hline P240 & 60.5 & 56.5 \\
\hline P400 & 36.5 & 33.5 \\
\hline P800 & 22.8 & 20.8 \\
\hline P1200 & 16.3 & 14.3 \\
\hline
\end{tabular}


TABLE II. Types of polymer pastes

\begin{tabular}{|c|c|c|c|}
\hline \multirow{2}{*}{ Content of abrasive grains } & \multicolumn{3}{|c|}{ Content of abrasive grains in polymer paste } \\
\cline { 2 - 4 } & $Z_{1}$ & $Z_{2}$ & $Z_{3}$ \\
\hline $\mathrm{P} 240$ & $\mathrm{P} 240 / Z_{1}$ & $\mathrm{P} 240 / Z_{2}$ & $\mathrm{P} 240 / Z_{3}$ \\
\hline $\mathrm{P} 400$ & $\mathrm{P} 400 / Z_{1}$ & $\mathrm{P} 400 / Z_{2}$ & $\mathrm{P} 400 / Z_{3}$ \\
\hline $\mathrm{P} 800$ & $\mathrm{P} 800 / Z_{1}$ & $\mathrm{P} 800 / Z_{2}$ & $\mathrm{P} 800 / Z_{3}$ \\
\hline $\mathrm{P} 1200$ & $\mathrm{P} 1200 / Z_{1}$ & $\mathrm{P} 1200 / Z_{2}$ & $\mathrm{P} 1200 / Z_{3}$ \\
\hline
\end{tabular}

\section{Results of the use of a polymer medium in abrasive flow machining}

The surface machining of the polymer product using each paste was performed for 10 samples. Achieved data sets were checked for normality using a chi-square test. In addition, the Q-Dixon test checked for a gross error in the result set.

Change in the roughness of the machined polymer surface can be described by the relationship in the form of the RIR (roughness improvement rate) [12]:

$$
R I R=\frac{S R_{\text {original }}-S R_{\text {after machining }}}{S R_{\text {after machining }}}[\%]
$$

where: SR_original - surface roughness $(R a)$ of the product before AFM treatment, SR_after_machining - surface roughness $(R a)$ of the product after AFM treatment.

The roughness changes calculated on this basis after abrasive flow machining are shown in figs. 7 and 8.

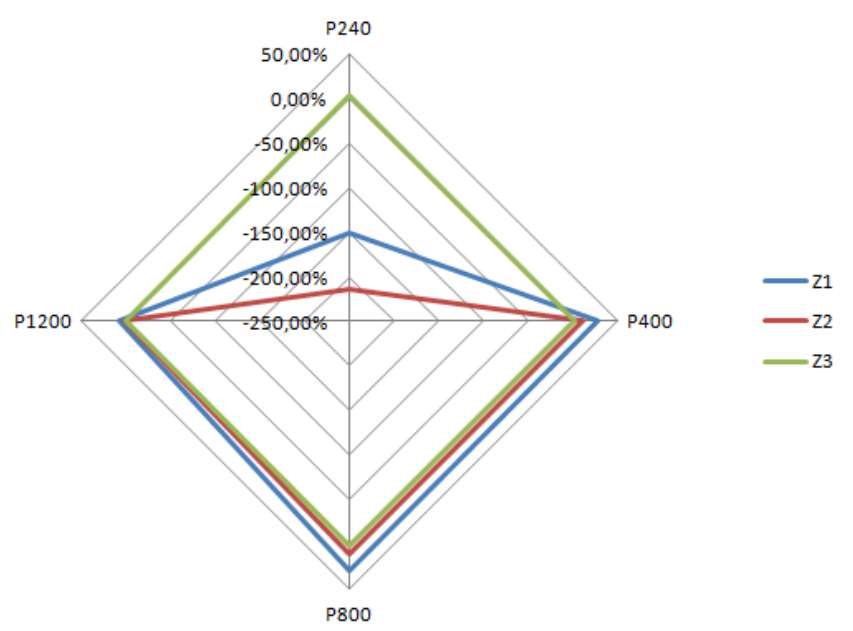

Fig. 7. Roughness parameters of PC polymer after abrasive flow treatment

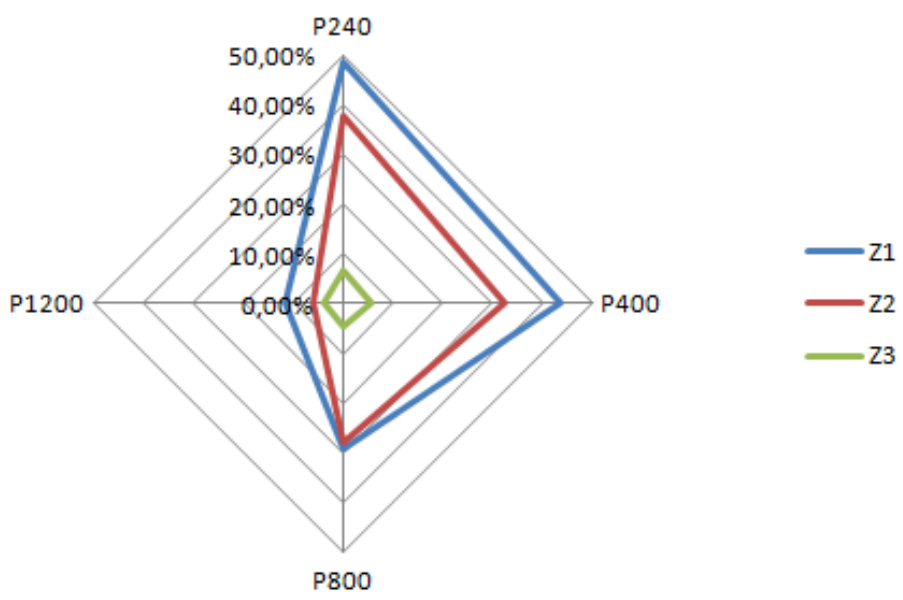

Fig. 8. Roughness parameters of ABS polymer after abrasive flow treatment 
Analysis of the results of roughness measurements of polymer products confirmed that the use of P1200/Z3 polymer paste did not improve the surface roughness.

Although the Z3 paste was used, the surface roughness of samples made of ABS material was significantly reduced, but in the case of samples made of PC the surface roughness increased. The reason for these discrepancies was the initial surface roughness value before machining: for ABS $R a=0.390 \mu \mathrm{m}$, for PC $R a=0.208 \mu \mathrm{m}$. The $R a$ parameter of the surface of the PC product after application of the P240 paste is about 2.5 times higher than before machining $(0.782 \mu \mathrm{m})$. The reason for the increase in the roughness parameter are plastic deformations resulting from grooving consisting in the formation of scratches and pushing of a part of the material above the polished surface. The PC surface after P400 abrasive grain machining had a $12 \%$ less roughness compared to the ABS surface.

Obtained results indicate that in the case of surfaces machined with Z1 and Z2 pastes, better roughness parameters (by $47 \%$ lower) were obtained compared with Z3 pastes.

The best results regarding the reduction of the surface roughness compared to the surface roughness before machining are presented in tab. III.

TABLE III. Reduction in the surface roughness after finishing

\begin{tabular}{|c|c|c|}
\hline Workpiece & Abrasive paste & $\begin{array}{c}\text { Reducing the surface roughness after ma- } \\
\text { chining, } \%\end{array}$ \\
\hline ABS product & $\mathrm{P} 240 / \mathrm{Z}_{1}$ & 44 \\
\hline PC product & $\mathrm{P} 800 / Z_{1}$ & 28 \\
\hline
\end{tabular}

Visual inspection of polymer samples was carried out before and after abrasive flow machining. Photos of samples are shown in figs. 9 and 10. Fig. 11 shows the abrasive paste before and after machining.

Based on measurements and roughness analysis of polymer samples after finishing, it can be stated that the polymer medium can be used for abrasive flow machining. It does not show visual traces of thermal decomposition and ensures that abrasive grains are maintained in the paste volume, and thus allows the removal of allowances from the workpiece surface.
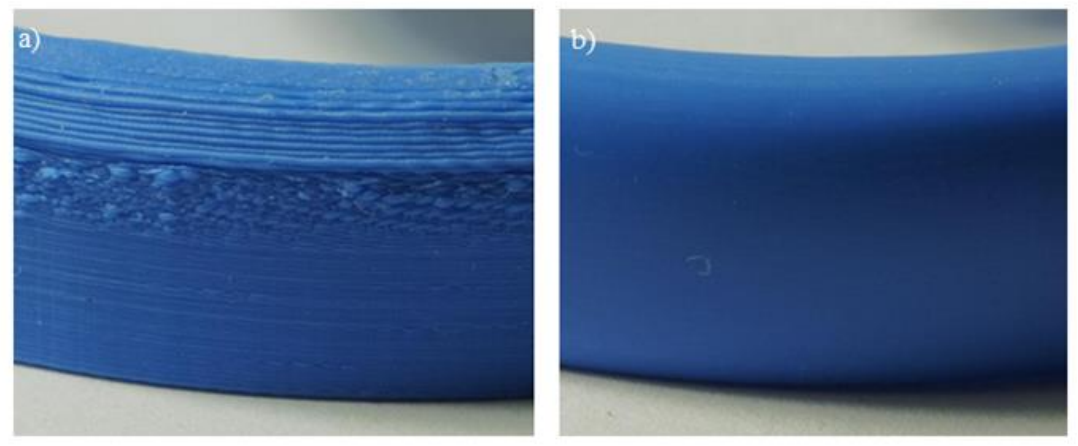

Fig. 9. ABS polymer surface: a) before finishing, b) after machining with abrasive polymer paste (after 10 cycles)
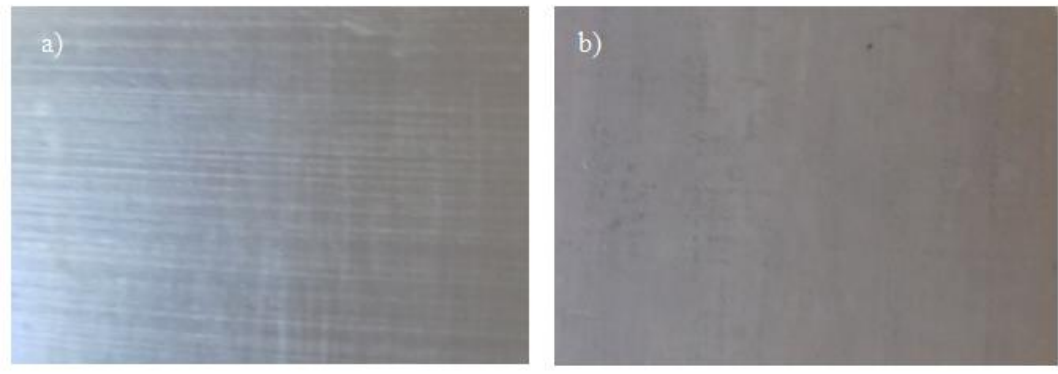

Fig. 10. PC polymer surface: a) before finishing, b) after machining with abrasive polymer paste (after 10 cycles) 

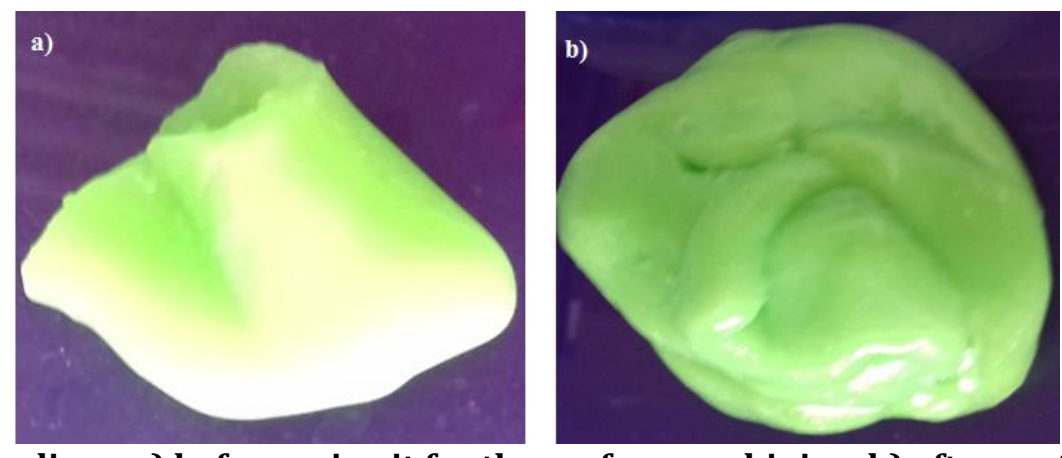

Fig. 11. Polymer medium: a) before using it for the surface machining, b) after surface machining (after 10 cycles)

\section{Summary and final conclusions}

Research and analysis of polymer plastic products lead to the conclusion that the use of abrasive flow machining allows for obtaining the desired surface quality of these products. It was confirmed that parameters of abrasive grains used in abrasive flow machining have an impact on the surface roughness of machined polymer products. The research results indicate that the size of abrasive grains in the polymer paste used for finishing should be equal to the unevenness of the sample surface. In addition, it can be stated that the polymer medium can be a component of the abrasive medium in abrasive flow machining.

\section{REFERENCES}

[1] Klepka T. (praca zbiorowa). „Nowoczesne materiały polimerowe i ich przetwórstwo. Część 1”. Lublin: Politechnika Lubelska, 2014.

[2] Wang C., Cheng K.C., Chen K.Y., Lin Y.C. "A study on the abrasive gels and the application of abrasive flow machining in complex-hole polishing”. Procedia CIRP. 68 (2018): 523-528.

[3] Kumara R., Murtaza Q., Walia R.S. "Three start helical abrasive flow machining for ductile materials". Procedia Materials Science. 6 (2014): 1884-1890.

[4] Uhlmann E., Schmiedel C.S., Wendler J. "CFD simulation of the abrasive flow machining process". Procedia CIRP. 31 (2015): 209-214.

[5] Butola R., Jain R., Bhangadia P., Bandhu A., Walia R.S., Murtaza Q. "Optimization to the parameters of abrasive flow machining by Taguchi method". Materials Today: Proceedings. 5 (2018): 4720-4729.

[6] Brown E., Jaeger H.M. "Shear thickening in concentrated suspensions: phenomenology, mechanisms and relations to jamming". Reports on Progress in Physics. 77, 4 (2014): 1-24.

[7] Hashimoto F., Yamaguchi H., Krajnik P., Wegener K., Chaudhari R., Hoffmeister H.W., Kuster F. “Abrasive fine-finishing technology". CIRP Annals - Manufacturing Technology. 65 (2016): 597-620.

[8] Brown E., Jaeger H.M. "The role of dilation and confining stress in shear thickening of dense suspensions". Journal of Rheology. 56, 4 (2012): 875-923.

[9] Oniszczuk-Świercz D., Świercz R., Dąbrowski L. „Mikroobróbka wykończeniowa - obróbka przetłocznościerna”. Mechanik. 8-9 (2016): 1132-1133.

[10] Kumar S., Hiremath S.S. “A review on abrasive flow machining (AFM)”. Procedia Technology. 25 (2016): 1297-1304.

[11] Sankar M.R., Jain V.K., Rajurkar K.P. "Nano-finishing studies using elastically dominant polymers blend abrasive flow finishing medium”. Procedia CIRP. 68 (2018): 529-534.

[12] Wang R., Lim P., Heng L., Mun S.D. "Magnetic abrasive machining of difficult-to-cut materials for ultrahigh-speed machining of AISI 304 bars”. Materials. 10 (2017): 1029-1041. 